\title{
'A CARGA MAIS PESADA DO MERCADO É A CARGA DOCENTE': SOBRE (DES)VALORIZAÇÃO, (DES/RE)CONHECIMENTO E (DES)RESPEITO A FIGURA DO PROFESSOR EM TEMPOS DE CRISE
}

Francisco Renato Lima ${ }^{1}$

\section{RESUMO}

A natureza do trabalho docente é, por si só, complexa e marcada por desafios que têm sido, nos últimos anos, objeto de reflexão das mais variadas abordagens epistemológicas no campo dos estudos educacionais. Na esteira dessas pesquisas, o presente estudo objetiva refletir sobre o papel do docente no contexto atual, apontando para sua excessiva sobrecarga horária de trabalho profissional e, ao mesmo tempo, sobre $\mathrm{o}$ enfrentamento às situações de desvalorização, falta de reconhecimento e desrespeito ao trabalho docente na sociedade. A costura das ideias apresentadas parte de um estudo bibliográfico e exploratório de natureza qualitativa, construído à luz de Althusser (1985), Arroyo (2000), Bastos (2009), Bourdieu (2004), Candau (2014), Chizzotti; Almeida (2019), DinizPereira (2011), Enguita (1991), Gasparini, Barreto e Assunção (2005), Libâneo (2018), Nóvoa (1995, 2009, 2017), Pimenta (2009), Tardif e Lessard (2005), entre outros. Em alusão metafórica à música 'A carne', imortalizada na voz de Elza Soares, com o verso 'a carne mais barata do mercado é a carne negra' em que o trabalho docente é associado como sendo o 'mais pesado do mercado', pelo excesso de demandas e o pouco reconhecimento e valorização. Semelhante a um efeito dominó, o modo como a figura do professor vem sendo tratada em seu percurso de inserção na cultura escolar e educacional brasileira; desencadeia uma série de questões, como: i) a desvalorização de seu

\footnotetext{
1 Mestre em Letras - Estudos da Linguagem pela Universidade Federal do Piauí- UFPI. Doutorando em Linguística pela Universidade Estadual de Campinas - UNICAMP. Professor Substituto da Universidade Estadual do Maranhão (UEMA). Coordenador de disciplinas do Centro de Educação Aberta e a Distância (CEAD/UFPI). ORCID: htt://orcid.org/0000-0002-1372-5444. E-mail: fcorenatolima@hotmail.com
} 
trabalho; ii) a sobrecarga de atribuições a ele destinadas; iii) os problemas de saúde; iv) uma crise de identidade. Um possível caminho ao enfrentamento e à superação dessa crise é a reestruturação do imaginário social sobre o trabalho docente, a fim de reconquistar sua sobrevivência cultural e profissional; e, com isso, tornar mais leve 'a carga docente' no atual mercado de trabalho.

Palavras-chave: Trabalho docente. Desvalorização. Sobrecarga de atividades. Saúde do profissional da educação. Identidade profissional.

\section{'THE HEAVIEST LOAD ON THE MARKET IS THE TEACHING LOAD': ABOUT (UN) VALUING, (UN / RE) KNOWLEDGE AND (UN) RESPECTING THE FIGURE OF THE TEACHER IN TIMES OF CRISIS}

\section{ABSTRACT}

The nature of teaching work is, in itself, complex and marked by challenges that have been, in recent years, the object of reflection of the most varied epistemological approaches in the field of educational studies. In the wake of these researches, the present study aims to reflect on the role of the teacher in the current context, pointing to his excessive overload of professional work and, at the same time, on coping with situations of devaluation, lack of recognition and disrespect for teaching work. in society. The sewing of the presented ideas starts from a bibliographical and exploratory study of qualitative nature, built in the light of Althusser (1985), Arroyo (2000), Bastos (2009), Bourdieu (2004), Candau (2014), Chizzotti; Almeida (2019), Diniz-Pereira (2011), Enguita (1991), Gasparini, Barreto e Assunção (2005), Libâneo (2018), Nóvoa (1995, 2009, 2017), Pimenta (2009), Tardif e Lessard (2005), among others. In a metaphorical allusion to the song 'A carne', immortalized in the voice of Elza Soares, with the verse 'the cheapest meat on the market is black meat', in which teaching work is associated with being the 'heaviest on the market', excessive demands and little recognition and 
appreciation. Similar to a domino effect, the way the figure of the teacher has been treated in his path of insertion in the Brazilian school and educational culture; triggers a series of issues, such as: i) the devaluation of their work; ii) the overload of duties assigned to him; iii) health problems; iv) an identity crisis. A possible way to face and overcome this crisis is to restructure the social imaginary about teaching work, in order to regain its cultural and professional survival; and, with that, make 'the teaching load' lighter in the current job market.

Keywords: Teaching work. Devaluation. Overload of activities. Health of the education professional. Professional identity.

\section{'LA CARGA MÁS PESADA EN EL MERCADO ES LA CARGA DE ENSEÑANZA': SOBRE (DES) VALORACIÓN, (DES / RE) CONOCIMIENTO Y (DES) RESPETO A LA FIGURA DEL MAESTRO EN TIEMPOS DE CRISIS}

\section{RESUMEN}

La naturaleza del trabajo docente es, en sí misma, compleja y marcada por desafíos que han sido, en los últimos años, el objeto de reflexión de los más diversos enfoques epistemológicos en el campo de los estudios educativos. A raíz de estas investigaciones, el presente estudio tiene como objetivo reflexionar sobre el papel del profesor en el contexto actual, señalando su sobrecarga excesiva de trabajo profesional y, al mismo tiempo, sobre cómo hacer frente a situaciones de devaluación, falta de reconocimiento y falta de respeto por el trabajo docente. en la sociedad La costura de las ideas presentadas parte de un estudio bibliográfico y exploratorio de naturaleza cualitativa, construido a la luz de Althusser (1985), Arroyo (2000), Bastos (2009), Bourdieu (2004), Candau (2014), Chizzotti; Almeida (2019), Diniz-Pereira (2011), Enguita (1991), Gasparini, Barreto e Assunção (2005), Libâneo (2018), Nóvoa (1995, 2009, 2017), Pimenta (2009), Tardif e Lessard (2005), entre otros. En una alusión metafórica a la canción 'A carne', inmortalizada en la voz de Elza Soares, con el 
verso 'la carne más barata del mercado es la carne negra', en la que el trabajo docente se asocia con ser el 'más pesado del mercado', demandas excesivas y poco reconocimiento y apreciación. Similar a un efecto dominó, la forma en que la figura del maestro ha sido tratada en su camino de inserción en la cultura escolar y educativa brasileña; desencadena una serie de problemas, tales como: i) la devaluación de su trabajo; ii) la sobrecarga de deberes asignados a él; iii) problemas de salud; iv) una crisis de identidad. Una posible forma de enfrentar y superar esta crisis es reestructurar el imaginario social sobre el trabajo docente, para recuperar su supervivencia cultural y profesional; y, con eso, hacer "la carga docente" más ligera en el mercado laboral actual.

Palabras clave: Trabajo docente. Devaluación Sobrecarga de actividades. Salud del profesional de la educación. Identidad profesional.

\section{INTRODUÇÃO}

Imagem 1 - Charge O Tempo 03/12/2019

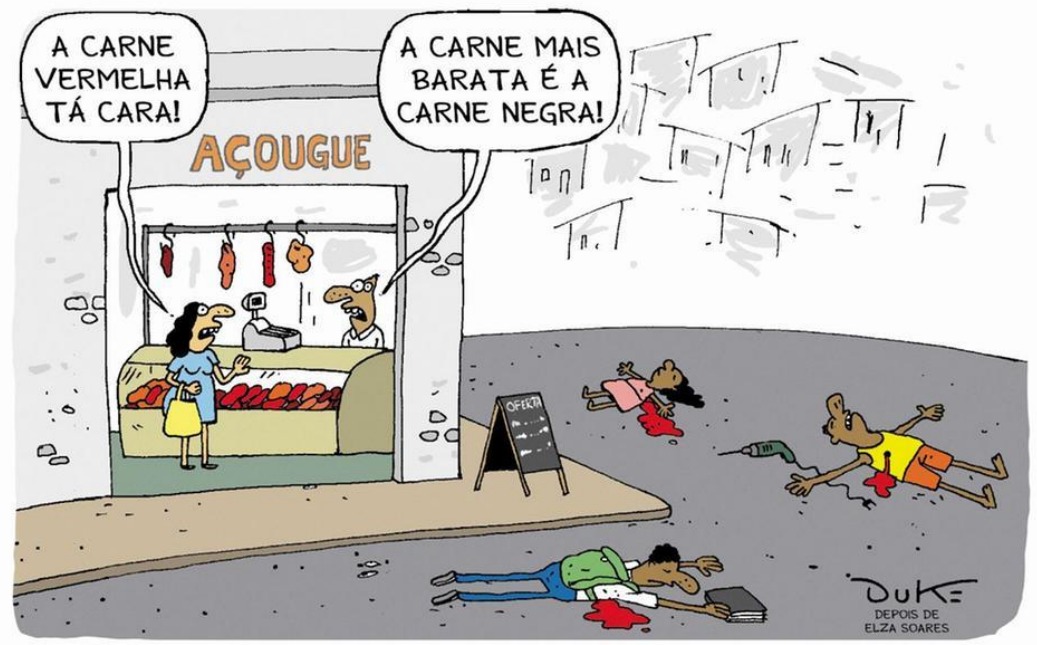

Fonte: Charge... (2019). 
A charge acima foi publicada no dia 03 de dezembro de 2019 no portal online O Tempo, de Belo Horizonte, o qual possui uma página diária exclusiva para a publicação de charges $^{2}$, que tematizam algum problema social em evidência ${ }^{3}$. Esta, em particular, chama atenção pelo fato de estabelecer uma relação intertextual com a música: A carne, composta por Seu Jorge, Marcelo Yuka e Ulisse Cappelletti; e eternizada na interpretação icônica ${ }^{4}$ do grupo Farofa Carioca e da musa Elza Soares, no álbum 'Do cóccix até o pescoço', de 2002:

\section{A carne}

A carne mais barata do mercado é a carne negra A carne mais barata do mercado é a carne negra A carne mais barata do mercado é a carne negra A carne mais barata do mercado é a carne negra A carne mais barata do mercado é a carne negra

Que vai de graça pro presídio

E para debaixo do plástico

Que vai de graça pro subemprego

E pros hospitais psiquiátricos

A carne mais barata do mercado é a carne negra A carne mais barata do mercado é a carne negra A carne mais barata do mercado é a carne negra A carne mais barata do mercado é a carne negra A carne mais barata do mercado é a carne negra

Que fez e faz história

Segurando esse país no braço

O cabra aqui não se sente revoltado

Porque o revólver já está engatilhado
E o vingador é lento

Mas muito bem intencionado

E esse país

Vai deixando todo mundo preto

E o cabelo esticado

Mas mesmo assim

Ainda guardo o direito

De algum antepassado da cor

Brigar sutilmente por respeito

Brigar bravamente por respeito

Brigar por justiça e por respeito

De algum antepassado da cor

Brigar, brigar, brigar

A carne mais barata do mercado é a carne negra A carne mais barata do mercado é a carne negra A carne mais barata do mercado é a carne negra A carne mais barata do mercado é a carne negra A carne mais barata do mercado é a carne negra

O propósito de trazer os dois textos é contextualizar a proposta metafórica apresentada neste estudo: o fato de que a sobrecarga horária docente é um dos trabalhos mais árduos do

\footnotetext{
2 Segundo Romualdo (2000, p. 21), o gênero textual "charge, enquanto mensagem icônica, não será recebida nem decifrada se o leitor não possuir informações necessárias para interpretá-la. A charge é um texto visual humorístico que critica uma personagem, fato ou acontecimento específico. Por focalizar uma realidade específica, ela se prende mais ao momento, tendo, portanto, uma limitação temporal".

3 Disponível em: https://www.otempo.com.br/charges. Acesso em: 10 dez. 2019.

${ }^{4}$ Videoclipe oficial disponível na plataforma digital online e de franco acesso, o YouTube, em: https://www.youtube.com/watch?time_continue=226\&v=yktrUMoc1Xw. Acesso em: 10 dez. 2019.
} 
contexto profissional e que, no entanto, é pouco visto, respeitado, reconhecido, valorizado e legitimado socialmente. "Os docentes vão incorporando novas funções e responsabilidades, premidos pela necessidade de responder às exigências dos órgãos do sistema, bem como da comunidade". (OLIVEIRA, 2012, p. 308-309). Nisso, o trabalho oculto desenvolvido por professores é imenso, repleto de atividades que ocupam, além de sua carga horária escolar remunerada no contracheque, grande parte de seu tempo disponível no ambiente doméstico, pois

[...] vai-se fisicamente para casa, mas o dia de trabalho não termina, pois as "tarefas" são muitas, além das inovações tecnológicas possibilitarem a derrubada das barreiras entre o mundo pessoal e o mundo profissional (celulares e principalmente e-mails). (MANCEBO; GOULART; DIAS, 2010, p. 09)

Ainda a título de justificativa dessa discussão, a imagem 02, a seguir, publicada no site SóEscola, em 02 de abril de 2017, explicita bem esse cenário:

Imagem 2 - Ninguém leva mais trabalho pra casa que o professor!

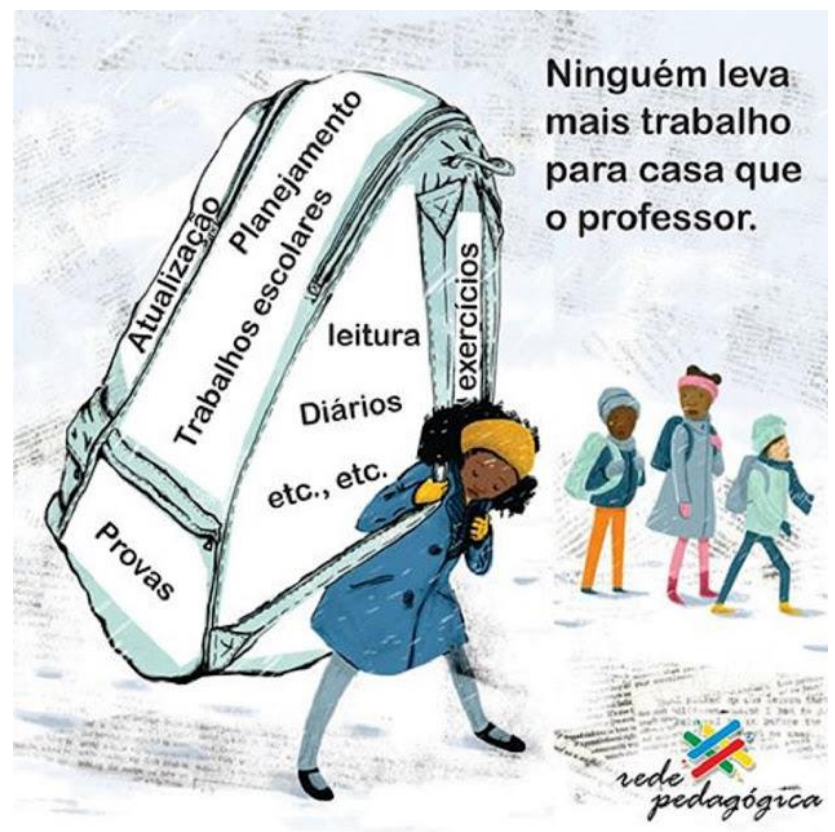

Fonte: Ninguém... (2017). 
Por contar disso, é possível dizer que 'a carga mais pesada do mercado é a carga docente', como explicita o título deste texto,

[...] a partir de abordagens que o situam no cenário brasileiro e internacional [...] problematizando as macro questões sobre a valorização, mas, sobretudo, verticalizando a análise de estudos e pesquisas sobre condições de trabalho e saúde dos profissionais da educação. (DOURADO, 2012, p. 297)

\section{A DESVALORIZAÇÃo E A SOBRECARGA DE TRABALHO}

DOCENTE: crise de identidade e saúde do profissional da educação

Para abordar a proposta anunciada, busca-se estabelecer uma reflexão crítica no sentido de analisar como a figura do professor vem sendo tratada em seu percurso de inserção na cultura escolar e educacional brasileira; com destaque para: i) a desvalorização de seu trabalho; ii) a sobrecarga de atribuições a ele destinadas; e como isso acarreta em iii) problemas de saúde; deflagrando assim, iv) uma crise de identidade.

(i)

Vive-se tempos aligeirados, em que a repetição do dia a dia e a pressa em chegar primeiro, muitas vezes, atropelam a natureza da consciência dos processos em que os sujeitos estão envolvidos. Uma das principais molas propulsoras dessa lógica é a moldura do capitalismo selvagem, a divisão e a desigualdade sistemática entre as classes sociais, fenômenos que estão atravessados pela noção de tempo, lugar, espaço e a dimensão que o trabalho ocupa na articulação do volume de atividades desempenhadas pelo homem.

Nesse sentido, cabe, à luz de Rohm, Lopes, Cavazotte, Lemos e Viana, respectivamente, mencionar a noção ampla de trabalho para, em seguida, restringi-lo à definição de trabalho docente e as elucidações pertinentes.

[...] o trabalho é uma condição fundamental na existência humana. Por meio dele, o homem se 
relaciona com a natureza, constrói sua realidade, significa-se, insere-se em contextos grupais, atua em papéis e finalmente promove a perenização de sua existência. Por viabilizar a relação dos indivíduos com o meio, em um dado contexto, o trabalho expressa-se como incessante fonte de construção de subjetividade, produzindo significado da existência e do sentido de vida. Todavia, o trabalho na pós-modernidade ocupa de tal forma um espaço no desejo do indivíduo que as pessoas buscam somente neste papel o sentido de suas vidas, inviabilizando a autorrealização plena do ser humano. (ROHM; LOPES, 2015, p. 333)

[...] as implicações do sentido do trabalho para as organizações e sociedades são amplas, uma vez que ele determina aquilo que as pessoas julgam ser legítimo no contexto ocupacional, o que estão ou não dispostas a tolerar, como os custos que as elites aceitam para direcionar as várias atividades do mundo do trabalho, até a facilidade com que indivíduos se dispõem a mudar hábitos para satisfazer os imperativos de novas tecnologias. Portanto, conhecer o sentido do trabalho para indivíduos e grupos hoje é um passo essencial para compreender o comportamento das pessoas no trabalho num mundo pós-moderno, no qual a dimensão profissional ainda tem papel fundamental para a formação da identidade e para o bem-estar das pessoas. (CAVAZOTTE; LEMOS; VIANA, 2012, p. 165)

As reflexões dos autores apontam para uma noção de trabalho situada nos liames do contexto da cultura do mundo pósmoderno, como uma atividade de entrelace entre a natureza organizacional das instituições e a subjetividade do sujeito trabalhador e, portanto, o modus operandi como essas categorias se articulam define a construção de um tipo particular de trabalho ou profissão na sociedade. Entre essas organizações e profissões, 
chama-se a atenção, respectivamente, para a escola ${ }^{5}$ e o professor, sujeito da educação, que desenvolve, especificamente, o trabalho docente, aqui, entendido a partir das reflexões seguintes:

O que caracteriza a profissão docente é um lugar outro, um terceiro lugar, no qual as práticas são investidas do ponto de vista teórico e metodológico, dando origem à construção de um conhecimento profissional docente. [...] as práticas docentes são extremamente difíceis e complexas, mas, por vezes, alimenta-se publicamente a ideia de que ensinar é muito simples, contribuindo assim para um desprestígio da profissão. (NÓVOA, 2009, p. 33)

O ensino aproxima-se bastante, assim, daqueles ofícios e daquelas profissões cujo espaço cotidiano de trabalho é marcado por uma grande autonomia e em que as atividades são desenvolvidas de acordo com representações, muitas vezes, renovadas, móveis, imprevisíveis na sua concretização e onde, por fim, a personalidade do trabalhador torna-se parte integrante do processo de trabalho. (TARDIF; LESSARD, 2005, p. 45)

Pontuadas essas definições, é importante destacar que o trabalho docente, enquanto atividade ou "profissão de interações humanas" como dizem Tardif e Lessard (2005), assume uma particularidade ainda mais específica em relação aos demais. Ele se desenvolve a partir de um "trabalho intelectual" nos termos de Guitton (2018), que tem como força motriz o domínio teóricoepistemológico e sistemático da cultura de uma determinada área do saber, e, utiliza-se desse saber, a fim de construir um lugar social no mundo do trabalho, conforme um "conjunto de requisitos profissionais que tornam alguém um professor" (LIBÂNEO, 2018, p. 69), o que constitui sua profissionalidade, uma noção que, segundo o autor, é composta de duas outras: profissionalização e profissionalismo. A primeira "refere-se às condições ideais que

\footnotetext{
${ }^{5}$ Neste texto, refere-se a 'escola', como como qualquer espaço formal e institucionalizado de educação, desde a Educação Infantil ao Ensino Superior (graduação e pós-graduação).
} 
venham a garantir o exercício profissional de qualidade" (p.69), como formação inicial e continuada, desenvolvimento de habilidades e competências, remuneração salarial, condições de trabalho etc. A segunda

[...] refere-se ao desempenho competente e compromissado dos deveres e responsabilidades que constituem a especificidade de ser professor e ao comportamento ético e político expresso nas atitudes relacionadas à prática profissional. (LIBÂNEO, 2018, p. 69)

Nesse mesmo contexto, essas noções são complementares e recíprocas e encaminham para o conceito de professoralidade, sugerido por Pereira (2013), o que abrange a dimensão subjetiva do sujeito experimentando a produção de si mesmo, por meio da reflexão sobre a prática docente. E nesse processo, "o sujeito se professoraliza e se subjetiva ao mesmo tempo. $E$, ao se professoralizar, contribui para a subjetivação de outros sujeitos" (PEREIRA, 2008, p. 02), e isto constitui a estética da professoralidade. Nas palavras do autor:

Chamo professoralização à operação proposital de certas tecnologias, certos aparatos e certos artefatos no sentido de pôr em movimento processos e percursos formativos, para si e para os outros. E é estudando a professoralização que alcanço vislumbrar a professoralidade. É investigando como me tornei o professor que sou, por que me tornei o professor que sou é que investigo a professoralidade. O professor que sou, o professor que estou sendo é apenas um estado, um estágio, um efeito dessa professoralidade que se professoraliza. Aquilo que sou é um caso particular de um vasto leque de possibilidades de eu ser. A realidade é um caso particular do possível. (PEREIRA, 2008, p. 06, grifos do autor)

Todo esse trajeto objetivou situar e reconhecer o papel do trabalho docente e seu lugar social na constituição da dimensão 'ser professor'. No entanto, apesar de toda essa relevância para a 
construção de uma democracia social e cidadã, circula na sociedade, e os professores 'sentem na pele' fortemente, a falta de reconhecimento e valorização de seu trabalho.

Não raro, nos últimos anos, são recorrentes nos diferentes tipos de mídia, algumas reportagens e notícias com dados assustadores. A exemplo, o Programa Profissão Repórter, da TV Globo, exibido no dia 18 de dezembro de 2019, com o seguinte tema:

Imagem 3 - Matéria de capa do Programa Profissão Repórter exibido na TV Globo

\section{Professores lutam contra salários baixos, doenças e até agressões para continuar na profissão}

Profissão Repórter mostra as dificuldades que os professores enfrentam dentro e fora da sala de aula. Doenças como ansiedade e depressão, salários baixos e até agressões de alunos são problemas recorrentes.

Fonte: Professores... (2019).

A leitura na íntegra do material disponível no site $\mathrm{G} 1$, no link acima, torna-se fundamental, para que se compreendam as dificuldades que os professores enfrentam dentro e fora de sala de aula. Segundo a investigação, in locu, realizada pela equipe do Programa, "em São Paulo, mais de 27 mil professores foram afastados das salas de aula entre janeiro e setembro deste ano por problemas de saúde", o que estar relacionado, por exemplo, a questões, como: jornada dupla de trabalho, salários baixos, situações de agressão, medo, ansiedade, pânico e depressão. O exemplo mais grave que denota o quão vulnerável e desvalorizados estão a escola e os professores em seu fazer docente é o caso ocorrido em Suzano (SP) e que, de certo modo, espelha uma realidade de todo o país. 
Dentre os muitos fatores que degradam, ferem e desvalorizam o espaço da educação, da escola, e, sobretudo, da figura do professor na sociedade, Gentili (2008, p. 45) aponta:

A precariedade salarial está associada, assim, à progressiva precariedade das condições de trabalho pedagógico nas escolas. $\mathrm{O}$ baixo investimento em educação resulta em péssimas condições de infraestrutura escolar, falta de material didático apropriado, ausência de bibliotecas e, como vimos, em salas de aula superlotadas. Os governos neoliberais tentaram atenuar essa situação mediante programas de modernização periférica que fizeram da chamada "transformação educacional" uma verdadeira caricatura do que deveria ser uma política pública democrática: compra de alguns poucos computadores, instalação de antenas parabólicas e aparelhos de vídeo, fax e data shows em escolas com goteiras permanentes, sem saneamento básico, com um único banheiro para meninos e meninas, muitas vezes sem giz e até mesmo sem energia elétrica.

As reflexões do autor conferem com um contexto social marcado, especialmente pela chegada de recursos, mídias digitais e aparelhagem tecnológica do mundo computacional nas escolas no início dos anos 2000. Tal fato ocorreu sem que, no entanto, estas instituições tivessem estrutura física e pedagógica (no relativo à formação de professores) para que absorvessem essas ferramentas e com elas, e a partir delas, produzissem significado sobre e para o ensino. De que adianta uma sala de Informática com computadores desligados, sem o manuseio produtivo à proposta educacional? TVs, data shows, entre outros recursos são importantes, mas onde eles ficarão guardados, se as goteiras destroem tudo em período de chuva? Lamentavelmente, é esse, então, o retrato de escola pública no Brasil, e tudo isso flagela o trabalho docente.

Gentili (2008, p. 47) prossegue com a reflexão:

O quadro se torna ainda mais dramático quando observamos a ofensiva ideológica conservadora lançada contra os professores nos últimos anos. Eles 
são responsabilizados pela profunda crise dos sistemas escolares e lhes é atribuída a culpa pelas péssimas condições de aprendizagem dos alunos e alunas, pelas altas taxas de repetência, pelas escassas oportunidades de inserção no trabalho para os recém-saídos do sistema escolar, pela violência dentro e fora das escolas e pela falta de participação cidadã nas questões mais relevantes que nossas sociedades devem enfrentar.

Essa "ofensiva ideológica conservadora lançada contra os professores" tem se intensificado particularmente no atual governo, que, abertamente, atenta e autoriza discursos e práticas desrespeitosas aos professores. O pesquisador brasileiro, Marcos Bagno (UnB), em um ato político no encerramento do XI Congresso Internacional da Associação Brasileira de Linguística (ABRALIN), em 8 de maio de 2019, em Maceió (AL), acentua esse fato:

A cada hora recebemos a informação de que a universidade $X$ só vai poder funcionar até setembro, de que a universidade $Y$ não tem como se manter funcionando depois de agosto, de que a universidade $Z$ vai ter de parar antes de julho. É a asfixia da educação, é o bombardeio da ciência, é a rejeição pura e simples da civilização, nada menos do que isso. Eu não tenho notícia de ter existido jamais ao longo da história um governo que tenha feito da educação a sua inimiga primordial. Mesmo os governos que não se empenharam em favor da educação eram hipócritas e demagógicos e, pelo menos no discurso, faziam o louvor da educação. Mas o desgoverno atual é tão bisonho, tacanho, tosco e burro que não é capaz nem sequer de cinismo. É a brutalidade em seu estado mais insano. (BAGNO, 2019, grifo nosso)

A cada dia, os discursos que ecoam na mídia são propostas arbitrárias, ilegítimas e tacanhas, que tentam diminuir, escarnecer, menosprezar e invalidar o trabalho árduo, digno e heroico de professores e professoras de todo o Brasil. Essa realidade é mostrada no documentário "Pro dia nascer feliz" (2006), de João Jardim, levando o telespectador a conhecer a realidade 'nua e crua' da escola 
brasileira, seja pública ou privada, evidenciando o desgaste de um sistema de Educação Básica no país. Uma análise desse material identifica alguns desses aspectos:

Das carrocerias dos superlotados caminhões paus de arara no sertão nordestino aos perigos e violências dos morros das grandes favelas brasileiras, o diretor desvela a face de uma escola perdida na imensidão de tantas 'ondas' de violência e descaso público, evidenciados por meio de problemas como: más condições de acesso e permanência na escola; falta de estrutura física, pedagógica e de segurança; orçamento financeiro limitado para a manutenção da escola; má qualidade da merenda pública; alto índice de evasão e defasagem de alunos; professores com formações insuficientes para atender aos desafios da prática; círculo da violência, desrespeito e diversos tipos de preconceito: entre alunos, entre professores e entre professores e alunos, principalmente estes agredindo e ameaçando os docentes em sala de aula; desmotivação para o trabalho por parte dos professores; enfim, uma pluralidade de mazelas e transtornos que permeiam os extremos do mapa do país, e que denunciam a situação de descaso, abandono, desrespeito e negligência, principalmente por meio das políticas governamentais para com a educação, embora seja esta o maior 'trunfo' do qual se utilizam em seus discursos de campanha política. (LIMA; BORGES; COSTA, 2017, p. 02)

Parece mesmo, que aqueles, que chegaram ao poder, desconhecem a força e o poder transformador que a educação possui. Tentam diminuir a educação e seus heróis, como o brasileiro Paulo Freire, maior educador do século XXI, reconhecido mundialmente, que tem sofrido ataques diários a sua figura, por exemplo: i) o Projeto de Lei 3.033, de 2019, apresentado pelo Deputado Sr. Carlos Jordy do PSL/RJ, em 21 de maio de 2019, alegando que "a revogação da lei que declara Paulo Freire Patrono da Educação Brasileira se impõe diante da calamidade da educação 
nacional" (BRASIL, 2019, p. 02); e ii) a declaração de 16 dez. 2019, do presidente Jair Bolsonaro, referindo-se a Paulo Freire, como 'energúmeno', conforme detalhada em matéria assinada por Guilherme Mazui (2019), no Portal G1. Estes e tantos outros constituem o discurso do recalque, da inveja e da incapacidade intelectual e cognitiva de compreender sua luta e sua história na construção letrada e cidadã do país.

Analisando o teor da fala do presidente, o professor Carlos Eduardo Araújo (2020, p. 01), em um lúcido e crítico artigo, rebate-a:

O ignóbil vocábulo seria mais bem utilizado por Bolsonaro, num ato de absoluta auto sinceridade, ao mirar-se no espelho. Num socrático exercício de autoconhecimento, ele não teria escolhido uma denominação mais adequada à sua própria e execrável figura. Assim, a palavra energúmeno, cujos sinônimos possíveis listamos: imbecil, ignorante, idiota, pateta, tonto, boçal, inepto, estúpido, tapado, besta, burro, estulto, abestado, desequilibrado, descontrolado, desatinado, desnorteado, fanático, furioso, exaltado, louco, arrebatado, possuído, possesso, endemoniado, endiabrado, não encontraria melhor e mais desqualificado destinatário naquele que a proferiu.

Diante desse cenário, Paraíso e Ranniery (2019, p. 1405) consideram esse:

Momento assustador para todos/as nós que acreditávamos que havíamos iniciado um percurso sem volta, na caminhada pela erradicação das injustiças sociais e educacionais ainda tão dramáticas no Brasil. Subitamente, damo-nos conta que muitas de nossas conquistas sociais, educacionais e curriculares das últimas décadas estão por um triz. Vemos todos os dias direitos sendo perdidos; conquistas sociais e culturais sendo atacadas; vidas sendo aniquiladas com o aprofundamento de moralismos, discriminações, pobreza e injustiças de todo o tipo. 
Portanto, o que se percebe é a materialização da crítica feita nos versos da canção:

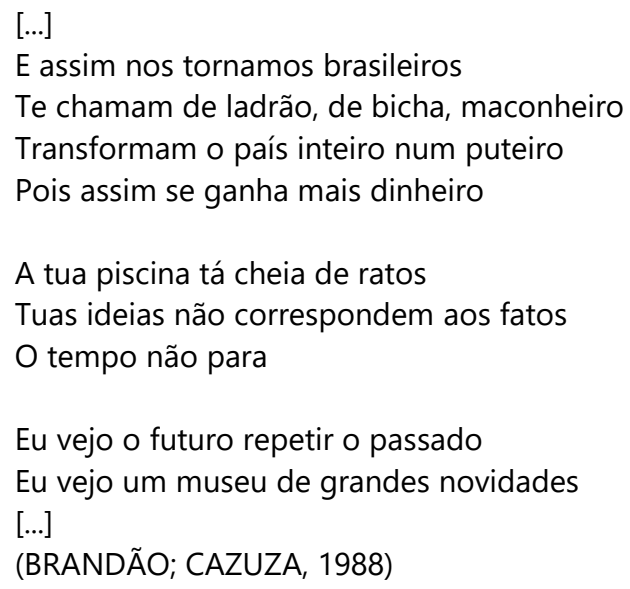

Nesse vendaval de insultos, de desrespeito às minorias e aos menos favorecidos social e economicamente, tenta-se, a todo custo, desvalorizar a força do trabalho docente e a figura do professor, profissional que luta diariamente pela educação e pela transformação social e cidadã que ela possibilita.

Todos esses ataques favorecem um quadro de desânimo e de desvalorização ao trabalho docente em várias dimensões, dentre elas: i) professores que já são formados e estão em atividades docentes em sala de aula e sentem o desprestígio autorizado nesse discurso; ii) estudantes concluintes do Ensino Médio, que não sentem-se atraídos pela carreira docente, em virtude das ameaças e incertezas que rondam a esfera educacional; e iii) professores em formação: estudantes de licenciatura (em especial, das áreas humanas e sociais) são os mais atacados e sentem-se desmotivados à rotina de um curso superior, em virtude da falta de perspectivas e investimentos na área, marcados, sobretudo, pelo corte de bolsas de estudo.

Na percepção de Chizzotti e Almeida (2019, p. 1399):

O novo governo difundiu um discurso iracundo sobre a educação nacional, responsabilizada por um imaginário insucesso na formação da juventude e, por essa razão, merecedora de uma intervenção 
coercitiva em todos os domínios da educação, a fim de coibir fantasiosos riscos do sistema de ensino, tais como: ameaça de perversão ética da juventude, adoção de ideologias desviantes e conversão ao ideário político da esquerda.

O discurso oficial propôs uma retórica difusa de saneamento ao que considerou descaminhos da educação brasileira e adotou uma eloquência agressiva contra o magistério. Essa retórica foi sequestrada por segmentos de partidos políticos e insuflados pelos meios midiáticos, propondo vigilância nas atividades docentes e denúncias sobre pretensas violações ao ideário oficial. Os ideólogos do novo governo difundiram narrativas depreciativas da educação e aviltantes aos educadores. Apoiados em um discurso populista, derivaram para a proposta de militarização das escolas e inclusão de militares na gestão da escola pública, com a criação de escolas cívico-militares, a pretexto de salvaguardar a integridade moral dos educandos e garantir a disciplina destes.

Esse clima de hostilidade incomum, polarizado por um ambiente acusatório contra os docentes, conflagrou as discussões sobre a qualidade e os resultados do ensino, mas, em contrapartida, trouxe a questão do sistema de educação nacional para o debate político.

Sobre o último aspecto mencionado pelos autores, de fato, a situação de crise tem chamado a atenção de diversas frentes de representatividade social, que têm se assumido como campo ou esfera de forças de lutas e tomadas de posicionamentos (BOURDIEU, 2004; BAKHTIN, 2011). Nesses espaços, um dos principais agentes tem sido o próprio profissional da educação - o professor pesquisador ou "os intelectuais da educação", como Bomeny (2003) refere, incluindo, nesse grupo, nomes como Anísio Teixeira, Darcy Ribeiro e Paulo Freire -, quem, à luz de uma posição epistemológica, assumiram (século $X X$ ) a missão de modernizar o país através da educação. Tanto no passado, quanto hoje, século XXI, o que se tem em comum é o comprometimento com uma postura crítica, reflexiva e, de certo modo, até defensiva do lugar social e lugar de fala de cada 
sujeito, diante dos ataques sofridos. A propósito, a discussão apresentada neste texto, pode ser definida como fruto desse movimento de tomada de partido e de consciência cidadã diante do "debate político".

(ii)

Some-se a esse cenário de crise atual outro aspecto tratado neste texto: a histórica sobrecarga de atribuições e atividades destinadas ao professor, tornando sua 'carga a mais pesada do mercado', em alusão a metáfora inicial. Conforme Vieira (2003, p. 51), "é quase mais uma jornada realizada fora do principal local de trabalho. Isso tem muitas consequências sobre as condições de saúde, sobre a relação com a família, sobre a qualidade do trabalho".

As condições de trabalho nas escolas; a jornada diária, muitas vezes, de três turnos; os baixos salários, as novas formas de regulação do trabalho escolar, as avaliações classificatórias e excludentes aliadas às excessivas demandas e cobranças pedagógicas, por elaboração e correção de atividades, cadernos de exercícios, provas, testes, calendários de eventos, diários de notas preenchidos (agora, manuais e online), entre tantas outras exigências, configuram um quadro grave, que limita da capacidade de produção intelectual do professor e de sufocamento de suas energias, tanto no âmbito profissional, como pessoal.

O trabalho docente é fruto de uma elaborada atividade intelectual, que prescinde a constante reelaboração do conhecimento culturalmente acumulado. No dia a dia escolar, essa tarefa demanda planejamento, execução e avaliação constantes das metas e dos objetivos previstos para o ensino. No entanto, para que isso ocorra com qualidade e proficiência, são necessários tempo e investimento institucional, o que nem sempre se espelha na prática escolar institucionalizada, lócus no qual se percebe que a excessiva sobrecarga de atribuições inerentes ao trabalho docente é fruto de uma educação que busca reproduzir a sociedade na qual ela se insere. E, portanto, a lógica do sistema capitalista e dos interesses econômicos e financeiros faz com que a escola, enquanto "aparelho ideológico do estado", nos termos de Althusser (1985), reproduza a cultura dominante, constituindo uma forma do sistema garantir e perpetuar seus interesses, passando, muitas vezes, por cima de 
valores humanos e éticos, sensíveis à produção de um trabalho crítico e produtivo no contexto escolar.

A fim de dar conta de resultados, metas, números, índices estatísticos alcançados em avaliações de larga escala e explicitados em outdoors, constituindo, assim, um slogan positivo e vendável no mercado e na política educacional (EVANGELISTA, 2014), a escola exige do professor uma carga de trabalho demasiadamente pesada, transformando o trabalho intelectual e humano em uma proletarização do trabalho docente. Segundo Enguita (1991, p. 49):

\begin{abstract}
A categoria dos docentes [...] compartilha traços próprios dos grupos profissionais com outras características da classe operária. Para sua proletarização contribuem seu crescimento numérico, a expansão e concentração das empresas privadas do setor, a tendência ao corte dos gastos sociais, a lógica controladora da Administração pública e a repercussão de seus salários sobre os custos da força de trabalho adulta.
\end{abstract}

São característicos desse movimento a criação de um individualismo/isolamento forçado do professor, que não tem tempo para vivenciar experiências de trocas e parcerias produtivas com os pares, o que desfavorece um trabalho docente qualificado. Esses, e tantos outros fatores mencionados, vão criando uma certa desilusão em relação a ser professor, fazendo com que a profissão docente entre em um estado de crise que, segundo Nóvoa (1995), já ocorre há bastante tempo, tendo como consequências principais, a desmotivação pessoal, os altos índices de absenteísmo e de abandono, a insatisfação e a indisposição para o enfrentamento dos desafios que a carreira docente demanda. No Brasil, Diniz-Pereira (2011, p. 36) aponta que os sinais e as evidências de "uma profunda crise da profissão docente", vêm sendo percebidos, sobretudo, nas descontinuidades que (des) caracterizam as políticas de formação de professores e que, portanto, "as respostas dos governantes brasileiros para tal situação têm sido, via de regra, insuficientes, equivocadas e ineficazes", criando um distanciamento entre os estudantes e os cursos de licenciatura. 
Desse modo, fatores político-educacionais e didáticopedagógicos parecem, muitas vezes, juntarem-se para corromper os planos de 'ser professor' no Brasil. Essa desvalorização, somada a sobrecarga de atribuições inerentes ao trabalho docente, tem comprometido a saúde do profissional da educação, um fato que afeta não só o aspecto individual do professor, mas o coletivo, da categoria profissional da qual faz parte, desencadeando, assim, uma desestrutura no sistema educacional de formação e atuação docente.

(iii)

Uma pesquisa realizada por Bastos (2009, p. 09), com o objetivo de descrever e analisar as situações de mal-estar docente e os processos de adoecimento de professores que atuam nos ciclos iniciais da escola básica, chegou a resultados ilustrativos ao presente estudo:

[...] entre outras questões, a ocorrência de um quadro de adoecimento, caracterizado como stress, depressão e agravos emocionais, processos de ansiedade, angústia, desânimo e apatia. Ainda foram manifestados o choro compulsivo, irritabilidade, cansaço extremo, agitação, baixa concentração e queda no desempenho profissional. Detectou-se também, os transtornos relacionados ao uso abusivo da voz, revelados através da rouquidão constante, dor na garganta, sensação de falta de ar, alterações no timbre, intensidade e altura da voz, e até perda temporária de voz.

O desenvolvimento dessas e de outras patologias inerentes à situação é decorrente de alguns fatores: i) de um imenso 'trabalho invisível' desenvolvido pelos professores, em madrugadas e noites a fios, tentando organizar e dar conta da demanda de sua ação profissional; ii) do enfrentamento das situações de desgaste e desrespeito enfrentadas na sala de aula; e iii) das situações de assédio moral e autoritarismo vivenciadas entre chefes (diretores, coordenadores etc.) no ambiente de trabalho.

Essa soma de fatores invisíveis - nem percebidos, nem valorizados - faz com que o trabalho docente, hoje, não se distinga de outras categorias profissionais em relação à saúde ou doença. 
Assim, retomando a metáfora título deste texto, concorda-se com Perez (2016, p. 14), quando aponta que a carga docente, "independente do tipo de contratação, "é pesada", pois se configura a partir de um excesso de atividades", seja na rede pública ou privada e, em todos os níveis de ensino: da Educação Infantil ao Ensino Superior. (Grifos da autora e nosso)

A criação de um mal-estar generalizado tem implicações na saúde física e psiquiátrica (psicológica ou mental), criando, hoje, um alarmante quadro clínico de vulnerabilidade da saúde do docente. Cada vez mais, em diferentes estados e regiões do país, resultados como os da pesquisa de Bastos (2009) têm se tornado frequentes do cotidiano das escolas, criando um misto de desarranjo social em torno das perspectivas da profissão docente no Brasil.

Um fato que corrobora esse quadro, segundo Paro (2012, p. 601), é "o reconhecimento (não explícito) de que o salário do professor não é suficiente para propiciar-lhe condições mínimas de trabalho" fazendo com que o profissional tenha que 'desdobrar-se em mil' no cumprimento de tantas tarefas, a fim de, ao final do mês, ter condições mínimas de sobrevivência. Para Oliveira (2012, p. 308309), essas situações constituem "as estratégias mais sutis e menos visíveis de exploração", pois "os docentes vão incorporando novas funções e responsabilidades, premidos pela necessidade de responder às exigências dos órgãos do sistema, bem como da comunidade" e da lógica do sistema capitalista.

As condições de trabalho, ou seja, as circunstâncias sob as quais os docentes mobilizam as suas capacidades físicas, cognitivas e afetivas para atingir os objetivos da produção escolar podem gerar sobreesforço ou hipersolicitação de suas funções psicofisiológicas. Se não há tempo para a recuperação, são desencadeados ou precipitados os sintomas clínicos que explicariam os índices de afastamento do trabalho por transtornos mentais [...]. (GASPARINI; BARRETO; ASSUNÇÃO, 2005, p. 192)

No cerne desse caos, o aparato principal dos professores - a força intelectual - acaba sendo sugada pelas determinações e 
exigências de um sistema extremamente segregacionista e excludente para com aqueles que não se adequam ao movimento do mercado. Muitos docentes, hoje, em virtude das pressões e tensões vivenciadas no ambiente de trabalho ou relacionadas a ele, enfrentam o mal-estar, isolamento social e a depressão, encontrando-se, por conta disso, afastados do trabalho, via atestados ou licenças médicas.

Nas palavras de Vieira (2003, p. 8), "mais do que uma difícil situação conjuntural, os trabalhadores em educação vivem um processo de expropriação de identidade como componente e reflexo da redução do próprio papel da educação neste período histórico", fato que remete então, a discutirmos a deflagrada crise com a identidade docente.

(iv)

Os problemas anteriormente mencionados, seja relativos à desvalorização do trabalho docente; à sobrecarga de atribuições e aos problemas de saúde, deflagram, por fim, uma crise na identidade profissional docente. De acordo com Diniz-Pereira (2011, p. 35):

As dimensões centrais que caracterizam a crise são: a alteração do estado de legitimidade social por meio da violação de valores, normas e códigos socialmente estabelecidos e, consequentemente, a ruptura de uma situação de equilíbrio ou estabilidade, a imprevisibilidade dessa situação e a urgência de julgamentos, decisões e respostas por parte dos envolvidos.

Acrescentando à discussão, Nóvoa (2009, p. 44) chama a atenção para o fato de que:

Nas sociedades contemporâneas, o prestígio de uma profissão mede-se, em grande parte, pela sua visibilidade social. No caso dos professores estamos mesmo perante uma questão decisiva, pois a sobrevivência da profissão depende da qualidade do trabalho interno nas escolas, mas também da sua capacidade de intervenção no espaço público da educação. Se os programas de formação não compreenderem esta nova realidade da profissão 
docente passarão ao lado de um dos principais desafios deste princípio do século XXI. (Grifo nosso).

Concordando com o autor, na sociedade brasileira não se percebe essa 'visibilidade social' positiva para com os professores. As discussões, até aqui empreendidas, demonstram justamente o contrário: do ponto de vista político, a educação e seus legítimos representantes (os professores), vêm sendo, sem melindres verbais ou morais, cada vez mais destratados.

Mais do que nunca, esse cenário compromete as perspectivas e o lugar social ocupado pelo professor, construindo uma degradação da imagem social docente. Nisso, a identidade docente "tende a ser afirmada frente à nova descaracterização da escola e da ação educativa" (ARROYO, 2000, p. 22), sendo definida, portanto, a partir das mudanças sociais; das relações internas, específicas do sujeito; e das relações externas do mercado de trabalho educacional. Nessa perspectiva, Pimenta (2009, p. 19) afirma:

Uma identidade profissional se constrói, pois, a partir da significação social da profissão; da revisão constante dos significados sociais da profissão; da revisão das tradições [...] constrói-se, também, pelo significado que cada professor, enquanto ator e autor, confere a atividade docente em seu cotidiano a partir de seus valores, de seu modo de situar-se no mundo, de sua história de vida, de suas representações, de seus saberes, de suas angústias e anseios, do sentido que tem em sua vida: o ser professor. Assim, como a partir de sua rede de relações com outros professores, nas escolas, nos sindicatos, e em outros agrupamentos.

Ou seja, a identidade docente é, como qualquer outra identidade profissional, um campo de movências de sentidos e valores construídos sob uma cultura e uma ideologia que, conforme os interesses daqueles que detêm o poder, vão sendo construídas a partir de um campo de lutas, interesses, compromissos e comprometimento social com o trabalho docente. Nos termos de Diniz-Pereira (2011, p. 48, grifo nosso): 
[...] a partir do momento que se assume a condição de educador - ou seja, quando a pessoa se coloca diante de outras e estas, reconhecendo-se como alunos, identificam-na como professor - que se inicia efetivamente o processo de construção da identidade docente. Mesmo que essa pessoa já tenha se imaginado nessa condição anteriormente, é só a partir da experiência concreta que esse processo será desencadeado. Tal constatação inevitavelmente nos faz pensar na inadequação dos cursos de formação inicial de professores do Brasil e de outros países, em que o estudante é capaz de concluir seu percurso na instituição formadora sem nunca ter assumido efetivamente o papel docente.

Assim, ser professor perpassa primeiro, pela ideia de autoaceitação e reconhecimento de si diante de uma comunidade e de um grupo social específico; em seguida, pelas instâncias de recepção e valorização de sua prática, constituindo, assim, um contínnum interacional entre as intenções docentes e discentes. Para que isso ocorra de maneira significativa é necessário que, durante todo o trajeto de formação, as dimensões teoria e prática sejam ajuizadas como fundamento valorativo de uma identidade em construção. Segundo Brzezinski (2001, p. 119):

Com essa identidade, o professor é o profissional dotado de competência para produzir conhecimento sobre o seu trabalho, em tomar decisões em favor da qualidade cognitiva das aprendizagens escolares $\mathrm{e}$, fundamentalmente, de atuar no processo constitutivo da cidadania, do "aprendente", seja ele criança, jovem ou adulto.

Articuladas essas dimensões, acredita-se então que, mesmo em face às situações de conflito e desafio que permeiam o território da educação, a identidade docente é oriunda das realizações concretas que sinalizam a ideia de mudança e transformação social, exigindo do professor a redefinição de seu saber e de seu fazer a serviço de uma educação crítica, reflexiva e democrática. Esse desafio requer da educação e do professor a adoção de estratégias didático- 
pedagógicas e alternativas viáveis para a superação do flagelo social que tem corroborado um cenário de crise no campo educacional.

\section{DIANTE DA CRISE, APONTAMENTOS TEÓRICOS PARA A POSSÍVEL CONSOLIDAÇÃO DE PRÁTICAS}

Os tempos de crise são, a um só tempo, situações de perdas, desgastes, mas também, de possibilidades de, como uma fênix, renascer das cinzas e (re) construir um alicerce mais sólido para a sustentação das práticas que alimentam o seu fazer social a partir de um engajamento social e comprometimento político e ideológico com o fazer profissional. Isso tudo, ciente de que toda prática docente é delineada com base em uma conjectura histórica, cultural e ideológica, e, portanto, a "uma escolha de pedagogia inevitavelmente comunica uma concepção do processo de aprendizagem e do aprendiz. A pedagogia jamais é isenta. Trata-se de um meio que carrega sua própria mensagem" (BRUNER, 2001, p. 67).

Carregada, portanto, de ideologia, a prática docente e a linguagem responsável por sistematizá-la são, inevitavelmente, resultados das teorias que o professor estuda, daquilo que ele ler, escreve e produz, a fim de melhorar suas condições de trabalho. De tal modo, dar aulas, requer uma tomada de decisões ideológicas, pois, "toda e qualquer metodologia de ensino articula uma opção política - que envolve uma teoria de compreensão e interpretação da realidade", bem como, "uma concepção de linguagem quanto uma postura relativamente à educação" (GERALDI, 2012, p. 40-41, grifos do autor), um ato social, que segundo Freire e Shor (1986, p. 146) "é, simultaneamente, uma determinada teoria do conhecimento posta em prática, um ato político e um ato estético". Assim, teoria e prática caminham para o combate e crise, e o sustentáculo do trabalho docente.

Como possível alternativa para desatar esse nó históricocultural, Dias-da-Silva (1998, p. 39) aponta a necessidade de ter-se o professor como um:

[...] sujeito de um fazer docente que precisa ser respeitado em sua experiência e inteligência, em 
suas angústias e em seus questionamentos, e compreendido em seus estereótipos e preconceitos. Sujeito que deve ser reconhecido como desempenhando papel central em qualquer tentativa viável de revitalizar a escola (pública), pois se é sujeito, é capaz de transformar a realidade em que vive. E se é sujeito de um fazer, é também sujeito de um pensar.

Nóvoa (2017, p. 1121) pontua cinco posições para uma formação profissional de professores que vise firmar a posição como professor e afirmar a profissão docente, esquematizados a seguir:

Imagem 4 - Posições para formação de professores, enquanto formação profissional universitária

\begin{tabular}{|c|c|c|c|c|c|}
\hline $\begin{array}{c}\text { Disposição } \\
\qquad \underset{\text { pessoal }}{\downarrow} \\
\qquad\end{array}$ & $\begin{array}{l}\text { Interposição } \\
\text { profissional }\end{array}$ & •ـ & $\begin{array}{l}\text { Composição } \\
\text { pedagógica } \\
\qquad \downarrow\end{array}$ & $\begin{array}{l}\text { Recomposição } \\
\text { investigativa }\end{array}$ & •——ública \\
\hline $\begin{array}{l}\text { Tornar-se professor é } \\
\text { transformar uma } \\
\text { predisposição numa } \\
\text { disposição pessoal. } \\
\text { Precisamos de espaços } \\
\text { e de tempos que } \\
\text { permitam um trabalho } \\
\text { de autoconhecimento, } \\
\text { de autoconstrução. (p. } \\
\text { 1121) }\end{array}$ & & \multicolumn{2}{|c|}{$\begin{array}{l}\text { Aprender a agir como } \\
\text { professor é compreender a } \\
\text { importância deste } \\
\text { conhecimento terceiro [as } \\
\text { metodologias e as didáticas], } \\
\text { deste conhecimento } \\
\text { profissional docente, que faz } \\
\text { parte do património da } \\
\text { profissão e que necessita ser } \\
\text { alçado ao lugar que merece na } \\
\text { formação dos professores. (p. } \\
\text { 1128) }\end{array}$} & & $\begin{array}{l}\text { Ser professor é conquistar } \\
\text { uma posição no seio da } \\
\text { profissão, mas é também } \\
\text { tomar posição, } \\
\text { publicamente, sobre os } \\
\text { grandes temas educativos } \\
\text { e participar na construção } \\
\text { das politicas públicas. É } \\
\text { aprender a intervir como } \\
\text { professor. (p. 1130) }\end{array}$ \\
\hline \multicolumn{3}{|c|}{$\begin{array}{l}\text { [...] a formação deve permitir a } \\
\text { cada um construir a sua posição } \\
\text { como profissional, aprender a } \\
\text { sentir como professor. (p. 1123) }\end{array}$} & & \multicolumn{2}{|c|}{$\begin{array}{l}\text { A evolução dos professores depende } \\
\text { deste esforço de pesquisa, que deve } \\
\text { ser o centro organizador da } \\
\text { formação continuada. É assim que } \\
\text { aprendemos a conhecer como } \\
\text { professores. (p. 1128) }\end{array}$} \\
\hline
\end{tabular}

Fonte: Nóvoa (2017, p. 1121).

Sintetizando a proposta, Nóvoa (2017, p. 1130) acrescenta:

Não podemos firmar a nossa posição se, ao mesmo tempo, não afirmamos a profissão. Ao dizê-lo, quero marcar a dimensão colectiva do professorado e trabalhar no sentido de compreender que há um conhecimento e uma responsabilidade que não se esgotam num entendimento individualizado do 
trabalho docente. É esta dimensão colectiva, de construção interna, mas também de projecção externa, que quis apresentar ao longo da minha reflexão.

No Brasil, o 'ser professor' assume uma dimensão bastante ampla, complexa e imbricada, que, conforme Lima (2017, p. 120), envolve:

[...] os processos de formação docente, enquanto direito do professor, em situação de inacabado e que necessita de um contínuo aperfeiçoamento profissional; a definição da identidade profissional, no que se refere à superação dos dilemas históricos de sua fragmentação e que exige, portanto, a legitimação da sua cidadania; e a construção da carreira docente, em complementaridade aos demais enfoques, firma-se como um suporte de alcance a valorização profissional e desempenho em patamares de reconhecimento social exigidos pela sua própria função social, de mediador de possibilidades de aprendizagem. (Grifos do autor)

Os termos em destaque permearam a tessitura deste texto e, aqui retomados, convocam a pensar sobre a natureza dos fatores históricos, políticos, sociais, ideológicos e culturais que permeiam o trabalho docente envolvido por saberes, competências e habilidades diversas, dirigindo, assim, a atividade profissional docente. Nessa perspectiva, diante de cenários de crise, o papel da escola é transformar a experiência humana e superar as fragilidades do senso comum à luz da tradição epistemológica, fincada em instrumentais sólidos e constitutivos do aperfeiçoamento do trabalho intelectual.

É verdade que a educação cumpre funções variadas, mas todas elas se eclipsam diante da importância que adquire na sociedade atual a função de capacitação, para que as pessoas possam continuar progredindo ao longo do sistema educacional e para que possam realizar com êxito a transição ao mundo escasso do trabalho. (SACRISTÁN, 1996, p. 158, grifo nosso) 
E nesse processo, as visões também "se eclipsam", ou seja, coincidem ao apontar que os professores são principais responsáveis pela difusão de uma agenda cultural e de tomada de posição no cumprimento de uma agenda pedagógica e de formação para a cidadania. Assim, "a necessidade de mudança nas direções do trabalho do professor encontra-se no fato de que as estruturas básicas da escolarização se estabeleceram em outros tempos, com fins anacrônicos, enquanto a sociedade muda para uma era pósindustrial, pós-moderna" (HAGEMEYER, 2004, p. 75, grifo da autora), no entanto, muitas vezes, parece que a escola não acompanha essa mesma lógica e parece ainda proceder, em pleno século XXI, aos moldes do tradicionalismo que a constituiu no período colonial brasileiro.

Por fim, ainda segundo Hagemeyer (2004, p. 76), "no conflito caracterizado em posições tão diferenciadas", que demarcam o cenário de crise em torno do trabalho docente, uma alternativa de mudança, pressupõe "a restruturação educativa, como exercício de prudência e construção, na qual se ganhará ou se perderá a batalha pela profissionalidade docente". Uma "batalha" diária, de engajamento coletivo, crítico, político e ideologicamente definida, com a finalidade de reconquistar a sobrevivência cultural e profissional docente; e, com isso, tornar mais leve 'a carga docente' no atual mercado de trabalho.

\section{CONSIDERAÇÕES FINAIS}

Sem saudosismos sôfregos, conclui-se este texto, com o seguinte pensamento: 'ai que saudades dos tempos em que professor era figura respeitada na sociedade'. Um respeito relacionado ao saber que ele detinha e, portanto, a capacidade de transformação social que propunha. Do ponto de vista sócio financeiro e econômico, é claro, nunca se teve o merecido reconhecimento, valorização e respeito ao seu trabalho, mas, pelo menos, no sentido de reconhecimento e prestígio social, já se pode gozar. E, é ele que se espera reconquistar. 
A professora Vera Maria Ferrão Candau (2014, p. 34), uma das maiores pesquisadoras em educação, currículo e formação de professores no Brasil, corrobora esse pensamento:

O magistério foi considerado durante muito tempo uma profissão valorizada socialmente, de prestígio e reconhecimento pelo seu potencial humanizador e seu compromisso com a formação para a cidadania. Em geral, esta valorização não era acompanhada de condições de trabalho adequadas. O salário dos professores era módico e os estímulos para o desenvolvimento profissional escasso. No entanto, esta realidade não impedia que o magistério fosse visto e vivido como uma profissão que valia a pena por sua importância intelectual, ética e social.

Esta não é a situação que vivemos hoje. Junto às condições de trabalho precárias que a grande maioria dos professores enfrenta, é possível detectar um crescente mal-estar entre os profissionais da educação. Insegurança, estresse, angústia parecem cada vez mais acompanhar o dia a dia dos docentes. Sua autoridade intelectual e preparação profissional são frequentemente questionadas. Ser professor hoje se vem transformando em uma atividade que desafia sua resistência, saúde e equilíbrio emocional, capacidade de enfrentar conflitos e construir diariamente experiências pedagógicas significativas.

Uma possível válvula de escape desse quadro atual de crise, marcado por uma 'carga tão pesada', é, sem dúvidas, a reconstrução do imaginário social e coletivo sobre a figura do professor, o resgate de seu valor social. E, desta vez, não apenas o reconhecimento social, mas, fundamentalmente, a devida valorização e compensação salarial, tendo em vista que esta implica naquela, uma vez que, no contexto do capitalismo, ser remunerado dignamente, constitui uma condição sine qua non para a valorização pessoal e profissional.

Para finalizar, o escritor e ilustrador Alexandre Beck (2019), por meio do personagem Armandinho, na tirinha abaixo, dá o tom 
necessário à mensagem que se pretendeu defender ao longo destas páginas:

Imagem 5 - Tirinha de Armandinho
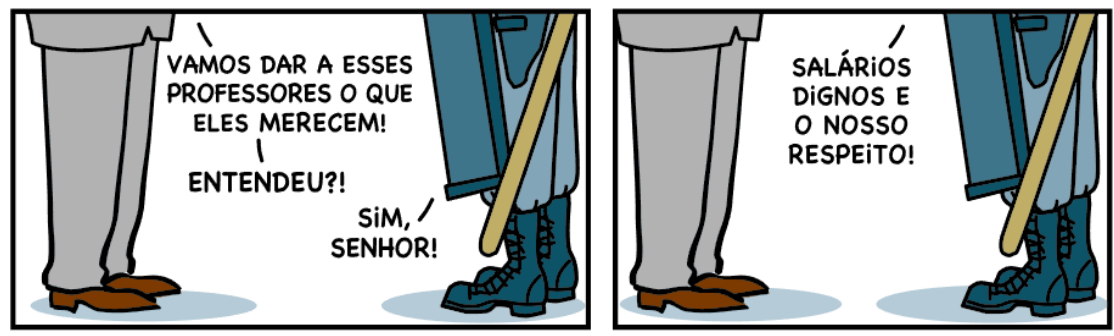

Fonte: Armandinho (2015).

\section{REFERÊNCIAS}

ALTHUSSER, Louis. Aparelhos Ideológicos de Estado: nota sobre os Aparelhos Ideológicos de Estado. 9. ed. Rio de Janeiro: Graal, 1985.

ARAÚJO, Carlos Eduardo. A demonização do legado de Paulo Freire na era Bolsonaro. Brasil 247, 4 jan. 2020. Disponível em:

https://www.brasil247.com/blog/a-demonizacao-do-legado-depaulo-freire-na-era-bolsonaro. Acesso em: 05 jan. 2020.

ARMANDINHO. Tiras Armandinho, 20 fev. 2015. Disponível em: https://tirasarmandinho.tumblr.com/post/111592346899/tirinhaoriginal. Acesso em: 15 dez. 2019.

ARROYO, Miguel G. Ofício de mestre: imagens e autoimagens.

Petrópolis: Vozes, 2000.

BAGNO, Marcos. Glorificação da Ignorância. In: ANGEL, Hildegard. Cada ato desse desgoverno é uma pulsão de morte, é uma perversidade sádica... Coluna da Hilde, 08 jul. 2019. Disponível em: http://www.hildegardangel.com.br/category/coluna-da-hilde/. Acesso em: 08 set. 2019.

BAKHTIN, Mikhail. Estética da criação verbal. Trad. Paulo Bezerra. 6. ed. São Paulo: Martins Fontes, 2011. 
BASTOS, Josane Aparecida Quintão Romero. O mal-estar docente, o adoecimento e as condições de trabalho no exercício do magistério, no Ensino Fundamental de Betim/MG. 2009. 149 f. Dissertação (Mestrado em Educação) - Programa de Pós-Graduação em Educação. Pontifícia Universidade Católica de Minas Gerais, Belo Horizonte, 2009.

BECK, Alexandre. Armandinho: Quadrinhos e tirinhas http://www.facebook.com/tirasarmandinho http://tirasbeck.blogspot.com/ -. Imagem de 20 fev. 2015.

Disponível em:

https://tirasarmandinho.tumblr.com/post/111592346899/tirinhaoriginal. Acesso em: 15 dez. 2019.

BOMENY, Helena Maria. Os intelectuais da educação. 2. ed. Rio de Janeiro: Zahar, 2003.

BOURDIEU, Pierre. Os usos sociais da ciência: por uma sociologia clínica do campo científico. São Paulo: UNESP, 2004.

BRANDÃO, Arnaldo; CAZUZA. O tempo não para. LP O tempo não para, Polygram, 1988.

BRASIL. Projeto de lei $\mathbf{n} .^{\mathbf{3}} \mathbf{3 . 0 3 3}$, de 2019. Apense-se ao PL1930/2019. (Proposto pelo Sr. Do Sr. Carlos Jordy). Declara São José de Anchieta patrono da educação brasileira e revoga a Lei $n^{\circ}$ Lei $n^{\circ}$ 12.612, de 13 de abril de 2012. Brasília: Câmara dos Deputados, 21 de maio de 2019. Disponível em:

https://www.camara.leg.br/proposicoesWeb/prop_mostrarintegra;jse ssionid=9E0BDB2D1094440E94C79C1A94B9A4D0.proposicoesWebE xterno2? codteor $=1757222 \&$ filename $=$ Avulso $+-P L+3033 / 2019$.

Acesso em: 20 set. 2019.

BRUNER, Jerome. A cultura da educação. Porto Alegre: Artmed, 2001.

BRZEZINSKI, Iria. Contribuição apresentada pela ANPED nas audiências públicas sobre as "Diretrizes para a formação inicial de professores da educação básica em nível superior". Revista Brasileira de Educação, São Paulo, n.16, p. 118-124, jan./abr. 2001. 
CANDAU, Vera Maria Ferrão. Ser professor/a hoje: novos confrontos entre saberes, culturas e práticas. Educação, Porto Alegre, v. 37, n. 1, p. 33-41, jan./abr. 2014.

CAVAZOTTE, Flávia de Souza Costa Neves; LEMOS, Ana Heloisa da Costa; VIANA, Mila Desouzart de Aquino. Novas gerações no mercado de trabalho: expectativas renovadas ou antigos ideais?

Cadernos EBAPE.BR, v. 10, n. 1, p. 162-180, 2012.

CHARGE O Tempo. $O$ tempo, Belo Horizonte, 03 dez. 2019.

Disponível em: https://www.otempo.com.br/charges/charge-otempo-03-12-2019-1.2268995. Acesso em: 10 dez. 2019.

CHIZZOTTI, Antonio; ALMEIDA, Maria Elizabeth Bianconcini de. Editorial. Revista e-Curriculum, São Paulo, v. 17, n. 4, p. 1399-1404, out./dez., 2019.

DIAS-DA-SILVA, Maria Helena Galvão Frem. O professor e seu desenvolvimento profissional: superando a concepção do algoz incompetente. Cadernos Cedes, n. 44, p. 33-45, abril, 1998.

DINIZ-PEREIRA, J. E. O ovo ou a galinha: a crise da profissão docente e a aparente falta de perspectiva para a educação brasileira. Revista Brasileira de Estudos Pedagógicos, Brasília, v. 92, n. 230, p. 34-51, jan./abr. 2011.

DOURADO, Luiz Fernandes. Editorial. Retratos da Escola, Brasília, DF, n. 11, v. 6, p. 297-299, jul./dez. 2012.

ENGUITA, Mariano Fernández. A ambiguidade da docência: entre o profissional e a proletarização. Revista Teoria \& Educação, Porto Alegre, n.4, p. 41-61, 1991.

EVANGELISTA, Olinda (Org.). O que revelam os slogans na política educacional. Araraquara: Junqueira \& Marin, 2014.

FREIRE, Paulo; SHOR, I. Medo e ousadia: o cotidiano do professor. 9. ed. Rio de Janeiro: Paz e Terra, 1986.

GASPARINI, Sandra Maria; BARRETO, Sandhi Maria; ASSUNÇÃO, Ada Ávila. O professor, as condições de trabalho e os efeitos sobre sua saúde. Educação e Pesquisa, São Paulo, v. 31, n. 2, p. 189-199, maio/ago. 2005. 
GENTILI, Pablo. Desencanto e Utopia: a educação no labirinto dos novos tempos. Petrópolis: Vozes, 2008.

GERALDI, João Wanderley. Concepções de linguagem e ensino de Português. In: GERALDI, João Wanderley (Org.). $O$ texto na sala de aula. São Paulo: Anglo, 2012, p. 39-46.

GUITTON, Jean. $\mathbf{O}$ trabalho intelectual: conselhos para os que estudam e para os que escrevem. Trad. Lucas Félix de Oliveira Santana. Campinas: Kírion, 2018.

HAGEMEYER, Regina Cely de Campos. Dilemas e desafios da função docente na sociedade atual: os sentidos da mudança. Educar, Editora UFPR, Curitiba, n. 24, p. 67-85, 2004.

LIBÂNEO, José Carlos. Organização e gestão da escola: teoria e prática. 6. ed. São Paulo: Heccus, 2018.

LIMA, Francisco Renato. Formação, identidade e carreira docente: endereçando itinerários teóricos sobre o "ser professor" na contemporaneidade. Debates em Educação, v. 9, n. 18, p. 119-135, 2017.

LIMA, Francisco Renato; BORGES, Vanessa Raquel Soares; COSTA, Catarina de Sena Sirqueira Mendes da. Discurso, variação e letramentos na escola: os modos de dizer na educação brasileira de norte a sul pelas câmeras do documentário 'Pro dia nascer feliz'.

Linguagens \& Cidadania, v. 19, p. 01-23, nº especial, jan./dez., 2017.

MANCEBO, Deise; GOULART, Samira M. S.; DIAS, Viviane da Cunha. Trabalho docente na UERJ (1995-2008): intensificação, precarização e efeitos de subjetivação. In: SEMINÁRIO PARA DISCUSSÃO DE PESQUISAS E CONSTITUIÇÃO DE REDE DE PESQUISADORES, 2., Anais Eletrônicos [...] Rio de Janeiro: IUPERJ, 2010.

MAZUI, Guilherme. Bolsonaro chama Paulo Freire de 'energúmeno' e diz que TV Escola 'deseduca. G1, Caderno Política, 16 dez. 2019. Disponível em: https://g1.globo.com/politica/noticia/2019/12/16/bolsonarochama-paulo-freire-de-energumeno-e-diz-que-tv-escoladeseduca.ghtml. Acesso em: 23 dez. 2019. 
NINGUÉM leva mais trabalho pra casa que o professor! Só Escola, 02 abr. 2017. Disponível em:

https://www.soescola.com/2017/04/ninguem-leva-mais-trabalhopra-casa-que-o-

professor.html?fbclid=IwAR1TiBTnTMDRufVNVNPGyWObZ55TRI2I4oc4JOd_MJ6xkrKB7Q-qD2LY5c. Acesso em: 23 dez. 2019.

NÓVOA, António (Org.). Profissão Professor. Porto: Porto Editora, 1995.

NÓVOA, António. Firmar a posição como professor, afirmar a profissão docente. Cadernos de Pesquisa, 47 (166), p. 1106-1333, 2017.

NÓVOA, António. Professores: imagens do futuro presente. Lisboa: Educa, 2009.

OLIVEIRA, Dalila Andrade. Entrevista: a saúde do profissional e as condições de trabalho. Revista Retratos da Escola, Brasília, DF, v. 6, n. 11, p. 301-313, jul./dez. 2012.

PARAÍSO, Marlucy; RANNIERY, Thiago. Confrontos e resistências nas políticas curriculares e educacionais: apresentação do dossiê temático. Revista e-Curriculum, São Paulo, v. 17, n. 4, p. 1405-1413, out./dez., 2019.

PARO, Vitor Henrique. Trabalho docente na escola fundamental: questões candentes. Cadernos de Pesquisa, São Paulo, v. 42, n. 146, p. 586-611, 2012.

PEREIRA, Marcos Villela. Educação e arte: a consolidação de um campo interminável. Trabalho apresentado à $31^{\text {a }}$ Reunião Anual da ANPED, Caxambu, 2008.

PEREIRA, Marcos Villela. Estética da professoralidade: um estudo crítico sobre a formação do professor. Santa Maria: Ed. UFSM, 2013.

PEREZ, Karine Vanessa. Jornada de trabalho real e invisível: uma análise sobre o cotidiano de docentes em instituições de ensino superior privadas. 2016. Trabalho apresentado ao $4^{\circ}$ Congresso Brasileiro de Estudos Organizacionais, Porto Alegre, 2016. 
PIMENTA, Selma Garrido. Formação de professores: identidade e saberes da docência. In: PIMENTA, Selma Garrido (Org.). Saberes pedagógicos e atividade docente. 7. ed. São Paulo: Cortez, 2009. p. 15-34.

PRO dia nascer feliz. Direção: João Jardim. Roteiro: João Jardim. Brasil. Produção: Flávio R. Tambellini e João Jardim. Copacabana filmes, documentário, 2006. DVD, drama, 87 min., color, $35 \mathrm{~mm}$.

PROFESSORES lutam contra salários baixos, doenças e até agressões para continuar na profissão. G1, Profissão Repórter, 19 dez. 2019. Disponível em: https://g1.globo.com/profissaoreporter/noticia/2019/12/19/professores-lutam-contra-salariosbaixos-doencas-e-ate-agressoes-para-continuar-naprofissao.ghtml?fbclid=IwAR1 ezHMo8t8yE6mBOGMhTak9MATaboO eKe1JxyQ5-udxp_as4DxRcCop7DE. Acesso em: 20 dez. 2019.

ROHM, Ricardo Henry Dias; LOPES, Natália Fonseca. O novo sentido do trabalho para o sujeito pós-moderno: uma abordagem crítica.

Cadernos EBAPE.BR, v. 13, n. 2, p. 332-345, 2015.

ROMUALDO, Edson Carlos. Charge jornalística: intertextualidade e polifonia: um estudo de charges da Folha de São Paulo. Maringá: Eduem, 2000.

SACRISTÁN, José Gimeno. Educação pública: um modelo ameaçado. In: SILVA, Tomaz Tadeu da; GENTILI, Pablo (Orgs.). Escola S.A.:

Quem ganha e quem perde no mercado educacional do neoliberalismo. Brasília: CNTE, 1996. p. 150-166.

TARDIF, Maurice; LESSARD, Claude. 0 trabalho docente: elementos para uma teoria da docência como profissão de interações humanas. Petrópolis: Vozes, 2005.

VIEIRA, Juçara Dutra. Identidade expropriada: retrato do educador brasileiro. Brasília: CNTE, 2003.

YUKA, Marcelo; JORGE, Seu; CAPPELLETTE, Wilson. A Carne. In: SOARES, Elza. Do cóccix até o pescoço. Salvador-BA: Maianga discos, 2002. CD. Disponível em: http://immub.org/album/dococcix-ate-o-pescoco. Acesso em: 10 dez. 2019. 
Submetido em: Março/ 2020.

Aceito em: Janeiro/ 2021. 